\title{
Tourism Destination Management in Montenegro - Constraints and Opportunities
}

\author{
Ljiljana Pjerotic, PhD Candidate
}

Faculty of Business and Tourism, Academy of Knowledge, Budva, Montenegro

\author{
Doi:10.5901/jesr.2014.v4n4p394
}

Email: Ipjerotic@t-com.me

\begin{abstract}
Although tourism has the potential to provide destinations with a number of benefits, the sector can also have substantial negative social, environmental and economic outcomes for the local community if it isn't managed effectively. Tourism destination management must ensure the balance between economic, social, cultural and environmental activities. For the sustainable development of tourism destinations, there is a need for a coordinated effort between all interest groups (tourism stakeholders from the public, private and civil sectors), through systematically developed and implemented management plans at all levels, especially at the local destination level, where tourism activities take place, tourists interact with service providers and with communities, and where tourism's positive and negative impacts are most felt. The paper deals with the problem of managing a tourism destination from the perspective of harmonizing stakeholders interests. It explores destination management in the Montenegrin tourist destinations, namely the level of stakeholders cooperation and the state of application of the concept of sustainable development at the local destination level. An empirical research was carried on the sample of 17 local tourist organizations in Montenegro. Findings and implications of the research are given in the paper. The results revealed: the problem of insufficient implementation of tourism development plans, the best aspect of marketing activities and the need for education, especially in the field of planning and product development. The results related to the application of the concept of sustainable development suggest the need for defining and tracking indicators of sustainability.
\end{abstract}

Keywords: tourism destination management, sustainable development, stakeholder cooperation

\section{Introduction}

Effective tourism destination management is being posed as a necessary prerequisite to achieve sustainable tourism development. The main preoccupation of managing a destination should be to find a balance between economic, ecological and social development goals. Therefore, satisfying the wishes, interests, and needs of tourists and the local population while also considering the specificities of the environment and infrastructure is a must. The key indicators of a destination's quality should be: tourist satisfaction, the business sector, i.e. tourism supplier satisfaction, the local population's quality of life and the environment's quality.

Managing sustainable development by a synergetic action of all stakeholders involved with the tourism destination will decisively contribute to strengthening its competitive position in the tourism market. Due to the properties of the destination and the tourism product itself, it is not possible to organize management by a hierarchical model of responsibilities and operational tasks. In all tourism destinations, this always has to do with smaller or larger interest groups that play a certain role in and bear a responsibility for managing a tourism destination. Therefore, their collaboration is the only viable option for management. For these reasons, it is necessary to secure communication channels and coordination methods among participants. Through this coordination and joint action each and every individual management tool can be realized, which, as a result, will increase their quality and contribute to the destination's sustainability.

\section{Destination Management}

In tourism theory and praxis, destination management is understood and defined in diverse ways. If we view a tourism destination, a so-called virtual organization, as consisting of independent organizations with certain mutually shared resources and business goals, then joint management is needed to manage these resources and goals. From this perspective, "destination management coordinates those tourism functions within the destination that cannot be carried out by individual tourism supply providers, or jointly stand a better chance to achieve the goals" (Magaš, 2008).

Managing a tourism destination includes all of the activities that are carried out by a coordinated management of a tourism destination:

- Marketing to attract more customers (tourists) to visit the destination; 
- Rendering and coordinating services to meet the expectations of the destination;

- Securing a sustainable environment (physical, social and economic) in which tourism is being developed (Jegdić, V.,Cvijanović,S., Sajfert, D., 2010, pp. 122).

Destination management in the Encyclopedia of Tourism (Jafari, 2000, pp.146) is defined as "(an) integrated managing process of any of the three kinds of destinations (urban, holiday, or rural). It covers four key elements: the destination's offer (tourist experience, the destination's image, and attractiveness), visitor mix (marketing research), marketing communication (awareness and promotion), and organizational responsibility (leadership and partnership)".

According to the World Tourism Organization (UNWTO, 2007, pp. 4) "destination management represents a coordinated management of all elements that make up a destination (attractions, hospitality, approach, marketing and prices)."

A shared attitude regarding the definitions of destination management is reflected in emphasizing the need to coordinate activities among various stakeholders. This has to do with the necessity to harmonize activity and the need for cooperative work in managing tourism development at a destination.

Achieving goals in managing a tourism destination depends on the capacity to meet tourists' needs and wishes. On one hand, this calls for sufficient knowledge of the market, and on the other hand, for good organization and coordination of activities for all factors that influence the value and effectiveness of making and realizing a tourism product. According to Buhalis (2000, page 100), the main goals of tourism destination management are: meeting consumer needs, maximizing profitability of local entrepreneurship, securing a long-term perspective for the local population, and optimizing the existent resources through sustainable development.

Effective tourism destination management includes: 1. communicating and coordinating activities, and 2. utilizing management tools: planning, communication with the market and distribution, monitoring success and gaining new knowledge through education (Boranić, Ž., Tomljenović, R., Čorak, S., 2011, pp. 24). Communicating and coordinating activities for every individual management tool utilized in tourism destination development at the destination provides a platform for joint action amongst stakeholders. Planning is considered a key management tool. As a starting point to establish sustainable development at a tourism destination, development plans should encompass all aspects of development, especially ecological, social and economic. Only planning that takes into consideration all aspects, starting with physical properties of the area, then the financial, market, social, as well as environmental aspects, can achieve the desired development vision. Tourism development production activities at a destination should include all relevant stakeholders, i.e. consider the needs of the private and public sector, and especially the needs of the local population. This kind of stakeholders approach to planning will render a synergic effect when producing and executing plans, which is of utmost importance for their successful implementation. Tourism planning without a comprehensive consultation process is likely to reduce the effectiveness of the process. Communication with the market is a management tool that encompasses all activities directed towards attracting tourists to a certain destination and soliciting them to buy certain products and services at the place of stay and during travel. Because of the distance between the buyers and the "products" at the moment of buying, communication in tourism plays a special role. These are concrete operational activities that largely encompass promotional activities, such as appearing at fairs, advertising and general public relations activities. Distribution in tourism happens by way of a series of independent intermediaries that connect producers and buyers through distribution channels. In comparison to other products and services that are delivered to the buyer, in tourism a buyer is brought to the product or service, which is what makes distribution in tourism specific and different. Monitoring efficiency is an instrument consisting of activities that monitor tourism turnover, guest satisfaction, as well as competitiveness and benchmarking analyses. Making such analyses takes strengthening the collaboration of different tourist stakeholders, and analyses results can contribute to their better business through enhancing the quality of their business policy and decision-making. In planning sustainable development, and in accordance with the idea of building "a society of knowledge," it's necessary to emphasize enhancing competence through continuous learning, so that education becomes an important management tool. Specific kinds and topics of education differ at each destination. Since an increase in knowledge directly affects the quality of all other management tools, it is extremely important to recognize these needs and deliver educational training accordingly. Aside from this, education is essential for realizing activities in tourism development plans. Education can be carried out in the form of seminars or workshops.

Stakeholder groups are included in the managing process via various individual management tools (planning, product and infrastructure development, communicating with the market and distribution, monitoring success and gaining new knowledge). Collaboration on any one of the management tools is achieved through communicating and coordinating activities. The question is then posed - who coordinates the activities? The World Tourism Organization argues in favor of founding a Destination Management Organization to coordinate and take care of all the factors that influence creating a tourism product at the destination, i.e. coordinate activities directed towards development of tourism 
at the destination. The current state of affairs in Montenegro is that there are representatives of interest groups within local tourism organizations that should be coordinating activities. However, praxis shows that this is not always so, and it often depends on individuals - the directors of tourism organizations.

\section{Research Methodology}

\subsection{Research Sample}

Research on destination management, stakeholder collaboration within tourism destinations in Montenegro, and implementation of the sustainable development concept was done on a sample consisting of directors from local tourism organizations in Montenegro, who were the representatives of the public sector, i.e. of the system which is responsible for managing the tourism destination. We considered that tourism organizations have the most comprehensive insight into the status of destination management and stakeholder collaboration, i.e. of the collaboration amongst all participants in the development of tourism at the level of the destination, as well as of the factors limiting collaboration. The tourism organization system in Montenegro consists of 19 local tourism organizations. Seventeen questionnaires were returned, which is a 89.5\% return rate, showing that the sample is representative. The research took place in November of 2013.

\subsection{Research Method}

The research instrument was a structured questionnaire that asked participants to answer questions about the state of the destination's management according to the following management tools: planning in the destination, communication with the market and distribution, monitoring success, and gaining new knowledge. Most of these were closed questions, while some were multiple choice containing lists and answers denoting intensity. A numerical scale of five scores was used to evaluate participant views regarding the level of development of individual management tools at the destination. The questionnaires were sent by email to representatives of the tourism organizations. Descriptive analysis was applied against the collected data, and then the arithmetic mean values and their standard deviation of the received scores were calculated, as well as the medians and quartiles.

\section{Research Results}

Below we present the review on the state of tourism destination management tools in Montenegro. Further on we give the research results on stakeholder collaboration and examples of concepts on sustainable development. For each of the management tools we first provide a general picture of the present condition. For questions requiring a yes/no answer, i.e. in nominal variables analyses, we present the frequency of certain answers, while with ranks, i.e. ordinary data, we show the arithmetic mean and standard deviation. The results acquired through this research are presented below.

Planning within the destination: The observed planning instrument was one of three plans usually made regarding the tourism development at a destination. These are: Tourism Development Plan, Tourism Marketing Plan, and Promotional Activity Plan. Bearing in mind the fact that a large number of tourism organizations make annual promotional activity plans that are not contained in their marketing plans, promotional activity plan was observed independently of marketing plan (namely, a promotional plan may exist although there is no tourism marketing plan). Each of the listed plans was investigated to see if they even existed at the destination at all. If they did, it was necessary to evaluate how they were implemented, as well as to assess the presence of the sustainable development concept. Then, the participants were asked to give their views about the limits of the plans' implementation.

The research shows that most of the tourism destinations have a promotional activity plan (94.1\%) and a strategic development plan (70.6\%), while marketing plans are the least present (41.2\%). Although the plans are a presumption of a system-coordinated development, they are effective only when they get implemented. According to the opinions of the tourism organization directors, marketing and promotional activities plans are better implemented than those on tourism development, and they were evaluated with a score of 3 . As much as $91.7 \%$ of the participants think there are existent limits to implementing the Tourism Development Plans. As for reasons for the slow realization of tourism development plans, directors of tourism organizations listed shortage of financial resources (91.7\%), limitations in human resources (25\%), lack of product development strategy (25\%), insufficient knowledge about market trends (16.7\%), and bad stakeholder cooperation (8.3\%). 
Table 1: Planning within the destination

\begin{tabular}{|l|c|c|c|c|}
\hline \multirow{2}{*}{ Plan } & \multicolumn{2}{|c|}{ Destinations having a plan } & \multicolumn{2}{c|}{ Plan implementation rating } \\
\cline { 2 - 5 } & No. & $\%$ & Arithmetic mean & Standard deviation \\
\hline Tourism development plan & 12 & 70.6 & 3.00 & 0.816 \\
\hline Marketing plan & 7 & 41.2 & 3.71 & 0.700 \\
\hline Promotional activities plan & 16 & 94.1 & 3.68 & 1.158 \\
\hline
\end{tabular}

Source: author's research, 2013; Note: total no. of destinations participating in the poll: 17

According to the scores given by the directors of tourism organizations, marketing plans are the best implemented, which received an average implementation score of 3.71. This result is not surprising because numerous scientists point out that marketing activity is actually the field where collaboration between interest groups is the most developed, which is the prerequisite for their better realization.

When speaking about limitations to implementing these kinds of plans, all of the poll participants spoke positively about this problem. As for the kind of limitations, the responses are similar to those about development plans. Namely, most objections related to the lack of financial means (100\%), then a passive attitude to market demands (42.85\%), and limitations in human resources (28.57\%). Following these are: poor collaboration amongst tourism stakeholders (14.28\%), lack of product development strategy (14.28\%) and insufficient knowledge of market trends (14.28\%).

When it comes to promotional activity plans, their achievement was evaluated with an average score of 3.68. These plans are short-term, operative (operational activities that represent a long and well-practiced part of tourism organizations' business) and quickly produce results. They are mostly carried out in collaboration with the private sector, which knows the market very well. However, even with implementation of promotional activity plans, most of the poll participants (80\%) thought limitations existed. Again, the most pronounced limitations were shortage of financial means $(81.25 \%)$, limitations in human resources (12.5\%), and the absence of a product development strategy (12.5\%). Next came a passive attitude towards the market demand (6.3\%), and insufficient knowledge of market trends (6.3\%). In contrast to the previously mentioned plans, bad collaboration among the carriers of activities was not listed at all as a limitation.

Implementation of a sustainable development concept: With this research we wanted to determine poll participants' standpoints on the concept of sustainable tourism development, which nowadays is the only development option for a destination to achieve long-term competitiveness on the tourism market. Generally, applying this concept to a destination's tourism development was evaluated with an average score of 3.29. Considering that the need to define a sustainability indicator received a high average score (mean score 4.0), it is obvious that the significance of the concept has been recognized. The analysis shows that 13 of the 17 tourism destinations participating in the poll are following the indicators of sustainable development (76.5\%). The most significant field that the destinations believe needs to be defined and adopted is ecology and environmental protection (median 1), followed by economic (median 2), and then social indicators (median 3). Also, when it comes to applying the concept of sustainable tourism, generally it may be said that the poll participants consider the concept completely acceptable, in terms of applying it in planning tourism development at the destination level.

Table 2: Mean value of scores on communication quality with the market and distribution

\begin{tabular}{|l|c|c|c|}
\hline \multirow{2}{*}{ Elements } & \multirow{2}{*}{ Number of destinations } & \multicolumn{2}{c|}{ Mean scores on communication with market and distribution } \\
\cline { 3 - 4 } & & Arithmetic mean & Standard deviation \\
\hline Propaganda/Advertising & 17 & 3.70 & 1.125 \\
\hline Promotional material & 17 & 4.06 & 0.998 \\
\hline Public relations & 17 & 3.94 & 0.998 \\
\hline Internet & 17 & 4.12 & 0.900 \\
\hline Agencies' offers & 17 & 2.94 & 0.998 \\
\hline
\end{tabular}

Source: author's research, 2013

Communication with the market and distribution: Concerning the problem of communicating with the market and distribution, the poll participants were asked to state their opinion about the quality from 1 to 5 on the numerical scale. The questions were grouped into the following categories: propaganda, promotional material, public relations, the 
Internet, and agency offers. In Table 2 the obtained mean values on communication with the market and distribution are presented.

From the mentioned scores, it may be deduced that, according to the directors of tourism organizations, propaganda/advertising is the worst section of the promotional mix in tourism destinations in Montenegro. Although this was the worst rated activity of all, it is worth mentioning that it is (due to the shortage of financial means) least applied compared to all other promotional activities. Also, agency offers represent a critical point that was very poorly rated by the poll participants. This means that according to tourism organization directors, tourism agency offers are considered a poor aspect of what's presented at the destination, and that possibilities for improvement can be found right there. According to this, I find it important to mention the ever more noticeable initiative of creating "destination management companies". Namely, numerous professional, and also scientific institutions, are stressing the need for agencies at the destination to more actively create more complex tourist products primarily using local resources. That is, the receptive tourist agencies that, contrary to the tour operators that are basically the intermediaries, play the role of organizers of complex tourism products - excursions, events, manifestations, professional gatherings, and so on. "They stimulate the immediate providers of services to a faster adjustment to the needs appearing in the market demand"(Trezner, 2008).

Monitoring success: When speaking about success, we researched how tourism turnover is monitored, guest satisfaction, and the scope of competitiveness and benchmarking analyses. Of all the listed success monitoring methods (Table 3), most attention was paid to tourist turnover (88.2\%), and then guest satisfaction (82.35\%). Expectedly, competitiveness (47.06\%) and benchmarking (47.06\%) analyses, being contemporary management methods, are still a lot less used, only by a little less than a half of the researched destinations. That might be the consequence of insufficient education or lack of means, i.e. lack of human resources needed for such analyses. However, from the level of scores given to analysis significance in managing a tourism destination (Table 3), it is visible that although the poll participants highly rated the necessity to monitor all the methods, they especially recognize the importance of conducting competitive analyses (mean value 4.63) and monitoring guest satisfaction (mean value 4.57).

Table 3: Application of success analyses

\begin{tabular}{|c|c|c|c|c|}
\hline \multirow{3}{*}{ Kinds of Analyses } & \multicolumn{4}{|c|}{ Destinations that implement success analyses } \\
\hline & \multirow{2}{*}{ No. } & \multirow[b]{2}{*}{$\%$} & \multicolumn{2}{|c|}{ Mean scores of analyses' significance } \\
\hline & & & Arithmetic mean & Standard deviation \\
\hline Tourist turnover & 15 & 88.2 & 4.53 & 0.6182 \\
\hline Guest satisfaction & 14 & 82.35 & 4.57 & 0.6227 \\
\hline Competitiveness analyses & 8 & 47.06 & 4.63 & 0.4841 \\
\hline Benchmarking analyses & 8 & 47.06 & 4.50 & 0.7071 \\
\hline
\end{tabular}

Source: author's research (2013); Note: total no. of destinations participating in the poll: 17

Continuous adoption of new knowledge: Continuous adoption of new knowledge is one of the fundamental tools of efficient destination management. Adopting, as well as exchanging knowledge, are essential prerequisites for recognizing and accepting tourism market trends, as well as for sustainable tourism development. Lifelong education related to sustainable development and management will create an effective destination management. The research has shown that as much as $64.7 \%$ of destinations conduct training for tourism destination management. Despite the high percentage of destinations that implement education, it has been evaluated with an average score of 2.91 for sufficiency.

Table 4: Education for the needs of tourism destination management

\begin{tabular}{|c|c|c|c|c|c|}
\hline \multirow{2}{*}{ Education } & \multirow{2}{*}{ Total no. of destinations } & \multicolumn{2}{|c|}{ Destinations that provide education } & \multicolumn{2}{|c|}{ Evaluation of education sufficiency } \\
\cline { 3 - 6 } & \multirow{2}{*}{ Conducting education } & No. & $\%$ & Arithmetic mean & Standard deviation \\
\cline { 3 - 6 } & 17 & 11 & 64.7 & 2.91 & 0.996 \\
\hline
\end{tabular}

Source: author's research, 2013 
Table 5: Significance rank of fields according to the need of education

\begin{tabular}{|l|c|c|c|c|}
\hline \multicolumn{1}{|c|}{ Field } & Number of destinations & Median & Upper quartile & Mod \\
\hline Planning & 17 & 1 & 2 & 1 \\
\hline Product development & 17 & 2 & 3 & 2 \\
\hline Communication with market and distribution & 17 & 3 & 3 & 3 \\
\hline Monitoring success & 17 & 4 & 4 & 4 \\
\hline
\end{tabular}

Source: author's research, 2013

Furthermore, the significance of education was analyzed (1-the most significant, 4-the least significant) to find which fields had an outstanding need for education. So, planning was evaluated as the field in which education is needed the most (median=1, mod=1). Then followed: product development (median=2, mod=2), communication with the market and distribution (median=3, mod=3), and monitoring success (median=4, $\bmod =4$ ).

Stakeholders' collaboration: Collaboration of interest groups is thought to be a fundamental prerequisite for efficient tourism destination management. This research shows that collaboration in tourism destinations in Montenegro is good. Namely, the poll participants evaluated the collaboration amongst interest groups in tourism development at the destination with an average score of 3.06. They have further evaluated the quality of collaboration per the fields of collaboration, i.e. per management tools. The mean value of all scores ranges between 2.88 and 3.59. The worst evaluation was collaboration in the field of planning (mean score 2.88) while the best rated was collaboration in the field of communication. Market and distribution (mean score 3.59) was also confirmed by research related to this topic made by the WTO, which pointed out that the collaboration between the public and private sector was the best developed in destinations' marketing (WTO, 2000). A relatively low score in the field of success monitoring points to poor data sharing amongst the participants in destination management that could better monitor the effectiveness of activities at the destination.

The research results show that tourism organization directors see the causes of poor collaboration primarily in the lack of planning documents on tourism development $(\bmod 1)$, poorly developed communication channels (mod 2), differing interests $(\bmod 3)$, lack of formal modes of collaboration $(\bmod 4)$, and finally, the least important, lack of a leader, i.e. activities coordinator (mod 5). The problem recognized in communication channels and differing interests was confirmed by a literature review in which different authors warn of the same problems and limitations that are encountered even by developed tourism destinations, as well as the question of how to provide better connection, communication and trust amongst interest groups at the destinations.

\section{Conclusion}

A system of tourism organizations represents a good foundation for tourism development. This research on the condition of managing tourism development at the destination level shows that in Montenegro's destinations there is strategic, marketing, and operative planning. However, their realization was evaluated poorly. A shortage of financial resources, limitations in human resources, a lack of product development strategy, and a passive attitude towards market demands were stated as reasons for the slow realization of plans. However, in order for tourism organizations to become the carriers of development projects in the future, it is necessary that they grow into contemporary destination management organizations. The Law on Tourism Organizations of Montenegro of 2007 foresees establishing tourism organizations in order to improve and promote tourism, and coordinate activities with businesses and other entities. However, it does not contain the legal base for establishing the destination management organization, nor is there grounds for taking over the function of tourism destination management by the tourism organizations. Tourism destination management requires the creation of certain legal, regulatory, and financial mechanisms that will stimulate and direct it. On the other hand, tourism organizations, considering their long-term focus on promoting and organizing manifestations and less on other management instruments, are not yet ready to take over the role of leader in destination management; they do not yet have the possibility to conduct coordinated activities amongst different stakeholder groups, and "to suffer the consequences of conflicts between political goals and market demands". (Manente, M., Minghetti, V., 2009, page 82). At the same time, no new organizations that might take up these tasks have been found.

Although at the moment, with the existent structure and jurisdiction, local tourism organizations in Montenegro are not capable to completely take over the management at the level of the tourism destination, their capacities for doing so should be strengthened. Because of that, it is necessary to stress the present trends in tourism that prioritize sustainable 
development, tourism destination management, and stakeholder collaboration.

Establishing and operating destination management organizations is especially important for the key, i.e. priority tourism destinations in Montenegro. The lack of legal capacities to establish these organizations certainly will not contribute to adequate management of tourism destinations in Montenegro.

\section{References}

Bakić, O. (2008). Destination management of modern tourism. Business Economics, no. 1, 209-222.

Boranić Ž., S., Tomljenović, R., Čorak, S. (2011). Cooperation between stakeholders in tourism destinations. In: Čorak, S. (ed.). Challenges of tourism governance, Book 5 . Zagreb: Institute for Tourism.

Bramwell, B., Sharman, A. (1999). Collaboration in local tourism policymaking. Annals of Tourism Research, 26(2):392-415.

Buhalis, D. (2000). Marketing the Competitive Destination in the Future. Tourism Management, 21(1), 97-116.

Jafari, J. (2000). Encyclopedia of Tourism. London: Routledge.

Jamal, T.B., Getz, D. (1995). Collaboration theory and community tourism planning. Annals of Tourism Research, 22(1): 186-204.

Jegdić,V., Cvijanović, S., Sajfert, D. (2010). The optimal model of tourism destination management. Industry, no. 3, 121-138.

Klimek, K. (2013). Destination management organisations and their shift to sustainable tourism development. European Journal of Tourism, Hospitality and Recreation, 4(2): 27-47.

Kunst, I. (2011). Tourism destination management in Croatia - threats and opportunities. In: Čorak, S. (ed.). Challenges of tourism governance, Book 5. Zagreb: Institute for Tourism.

Law on Tourism Organizations. The Official Gazette of R. of Montenegro, no. 11/2004,46/2007.

Magaš, D. (2008). Destination management - models and techniques. Opatija: Faculty of tourism and hospitality management.

Manente, M., Minghetti, V. (2009). Organizations and participants in destination management.

In: Popesku, J. (ed.) (2009). Tourism destination management. Beograd: Singidunum University.

Saftić, D., Težak, A., Luk, N. (2011). Stakeholder approach in tourism management: implication in Croatian tourism. 30th International Conference on Organizational Science Development "Future organization", Portorož, Slovenija.

Trezner, Ž. (2008). Receptive travel agency as a Destination Management Company (DMC). In:

Trezner, Z. (ed.). Destination Management Companies - handbook for understanding business and successful marketing. Zagreb: UHPA.

WTO (2007). A Practical Guide to Tourism Destination Management. Madrid: Author.

WTO (2000). Public-Private cooperation: Enhancing Tourism competitiveness. Madrid: Author. 